\title{
Antibacterial Activities of Cationic Porphyrins and Porphyrin Encapsulated Gold Nanorods on Bacterial Cell Lines
}

\author{
Hlapisi $\mathrm{N}^{1, *}$, Maliehe $\mathrm{TS}^{2}$, Oluwafemi $\mathrm{OS}^{2}$, Songca $\mathrm{SP}^{3}$, Linganiso $\mathrm{L}^{1}$, Motaung TE
}

\author{
Hlapisi $\mathbf{N}^{1, *}$, Maliehe TS², \\ Oluwafemi OS ${ }^{2}$, Songca SP3, \\ Linganiso $\mathrm{L}^{1}$, Motaung $\mathrm{TE}^{4,5}$
}

'Department of Chemistry, University of Zululand, Private BagX 1001, KwaDlangezwa 3886, SOUTH AFRICA.

${ }^{2}$ Department of Chemical Sciences, University of Johannesburg, Doornfontein Campus, P.O. Box 17011, Doornfontein 2028, South Africa, Centre for Nanomaterials Science Research, University of Johannesburg, Johannesburg, SOUTH AFRICA

${ }^{3}$ Department of Chemistry, University of KwaZulu Natal, Private Bag X 54001, Durban 4000, SOUTH AFRICA.

${ }^{4}$ Department of Chemistry, School of Science in the College of Science Engineering and Technology, University of South Africa, Preller Street, Muckleneuk Ridge, City of Tshwane, P.O. Box 392, UNISA 0003.

${ }^{5}$ Department of Chemistry, Sefako Makgatho Health Science University, P.O. Box 94,

Medunsa, 0204, South Africa

\section{Correspondence}

\section{Hlapisi N}

Department of Chemistry, University of Zululand, Private Bag X 1001, KwaDlangezwa 3886, SOUTH AFRICA

E-mail: nsisitha@gmail.com

History

- Submission Date: 19-03-2021;

- Review completed: 02-05-2021;

- Accepted Date: 01-06-2021.

DOI : 10.5530/pj.2021.13.141

Article Available online http://www.phcogj.com/v13/i5

\section{Copyright}

(C) 2021 Phcogj.Com. This is an openaccess article distributed under the terms of the Creative Commons Attribution 4.0 International license.

\begin{abstract}
Bacterial infections form part of the major causes of mortality and morbidity around the world more especially in developing and under-developed countries. Cationic porphyrins have been reported to display better efficacy in antimicrobial photodynamic therapy activity. The purpose of this study was to synthesise the cationic porphyrins; (TAP) and (TPyP) and evaluate their pharmacokinetics and metabolic interactions with the DNA gyrase subunit A. The antibacterial activity of the nano-conjugates was evaluated against Staphylococcus aureus (ATCC 25925), Enterococcus faecalis (ATCC 29212) and Klebsiella pneumoniae (ATCC 4352) using the micro-dilution assay without light. AutoDock Vina was used to assess the molecular interactions between ligands and the DNA gyrase subunit $A$. The SwissADME online tool was used to assess the pharmacokinetic properties of the nano-conjugates, while the ADMETlab online too was used to assess the ability to inhibit the hERG gene, human hepatotoxicity and mutagenicity. The test nano-conjugates showed broad-spectrum antibacterial activity against all tested bacterial strains with the MIC values in a range of $0.42 \pm 0.1$ to $2.6 \pm 0.7 \mathrm{mg} / \mathrm{ml}$. The nano-conjugates revealed good molecular interaction with DNA gyrase subunit A with their binding free energy in the range of -8.3 to $-8.7 \mathrm{kcal} /$ mol. They are predicted to be P-glycoprotein (P-gp) substrates, able to penetrate the blood-brain barrier and non-inhibitors of cytochrome P450 (CYP) isomers (CYP 2C19, CYP 2C9 and CYP 2D6). Both nanoconjugates have the potential to cause cardiotoxic and mutagenic effects but not hepatotoxic effects. The results show that the synthesized compounds have the potential as anti-bacterial PDT agents.
\end{abstract}

Key Words: Bacteria, Porphyrin, Antimicrobial.

\section{INTRODUCTION}

Diseases caused by bacteria, parasites and fungi have become a major problem globally, this is despite the exceptional advances in medicine that have been reported thus far ${ }^{1-3}$. The impact of these diseases is very panoptical in developing and underdeveloped countries due to the lack of modern medicine in these countries. Resistant antimicrobial pathogens are increasing progressively, hence the need for the current antimicrobials to be reviewed and renewed to improve effectiveness ${ }^{4-8}$. Advances have been made by the development and conjugation of new organic molecules with metal nanoparticles over the years for applications against resistant, and multiple drug-resistant bacteria.

The use of antimicrobial photodynamic therapy (aPDT) as a treatment modality entails the use of photosensitizers (PSs) and visible light for the induction of oxidative damage to the microbial pathogens including bacteria $a^{9,10,11,12}$. The method can be used as an alternative to traditional antimicrobial medicines in the treatment of localized infections. Reports have shown the use of cationic porphyrins to dominate anionic or neutral porphyrins in terms of antimicrobial activity ${ }^{13-16}$. The presence of chlorine, fluorine or nitro groups not only improves the polarity and lipophilicity of the photosensitizers but also improves their antitumor activity ${ }^{17-21}$. The addition of a central metal atom in the porphyrin structure also improves the porphyrin polarity and lipophilicity ${ }^{22}$. Figure 1 shows a simplified method for the synthesis of the desired cationic porphyrins and encapsulation of AuNRs.
Metal nanoparticles have been utilized since ancient times in the fight against pathogenic bacteria ${ }^{23-25}$. Due to simple synthesis, their distinctive photophysical properties, and their biocompatibility, gold nanoparticles (AuNPs) are used in various biological applications. Their surface plasmon resonance (SPR) has opened doors for the particles to be used in heating, sensing, imaging and drug delivery ${ }^{26-}$ 28. The synthesis of the nanoparticle can also be tuned to give the desired shape to improve the SPR frequency of absorption when irradiated with nearinfrared (NIR) light ${ }^{29,30}$. The light energy absorbed is converted to heat, generating higher temperature around the environment in which the nanoparticles are embedded. AuNRs can absorb and dissipate light in this way over a wider range of frequencies, compared to other shapes of nanoparticles; from the visible to the near infra-red, depending on their aspect ratio, and this makes them ideal candidates for photo-thermal antibacterial applications ${ }^{31-33}$.

The interest of this study is on two cationic porphyrins, TPyP and TAP, how they are used in the encapsulation of AuNRs, and their antibacterial activity against four drug-resistant bacteria without using light. Furthermore, molecular docking studies have become very popular in the field of drug discovery and design as this has been used as a tool to further understand how the ligands interact with specific protein targets. The second purpose of the research is therefore to explore the interactions of the two porphyrin compounds with the bacterial DNAgyrase enzyme, by using molecular docking studies using the Biovia Studio 4.1 visualizer, with the interaction with ciprofloxacin used as the control. 


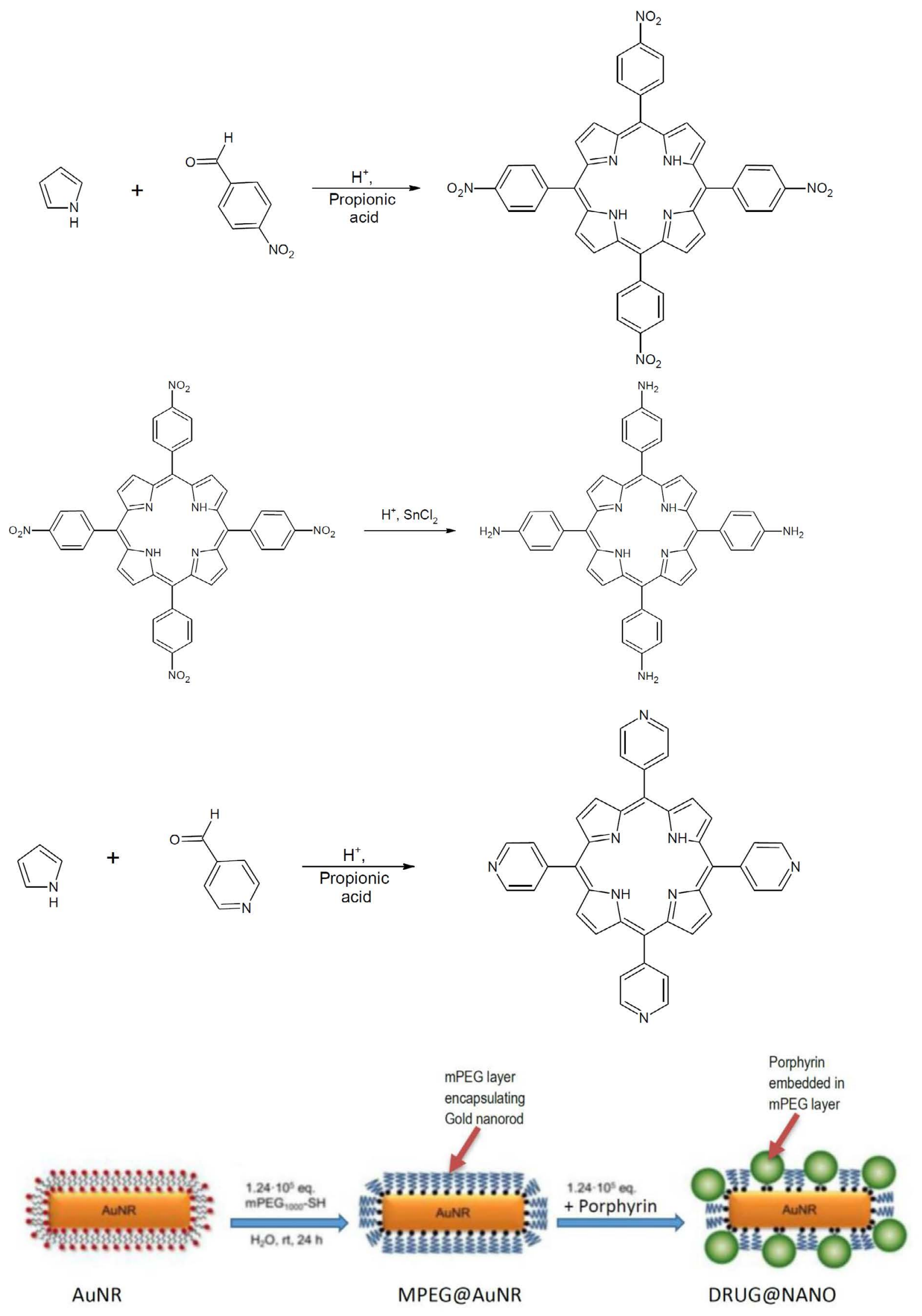

Figure 1: The synthesis of Cationic 5,10,15,20-tetrakis(4-pyridyl)porphyrin (TPyP) and 5,10,15,20-tetrakis(4-aminophenyl)porphyrin (TAP) and encapsulation of Gold Nanorods 
Also, the Swiss ADME online tool was used to assess the pharmacokinetic properties of the compounds, focusing on bioavailability and the potential to cross the blood-brain-barrier. The toxicological properties were investigated using the online server ADMETlab online tool based on the potential to inhibit the human ether-a-go-go-related (hERG) gene, the HHT and mutagenicity. To the best of our knowledge, the antibacterial activities of AuNRs encapsulated with these porphyrins have not been studied hence the study. These studies will provide the baseline antibacterial activity of these nano-conjugates without the use of light. Additionally, the computer simulations of the bacterial DNA-gyrase interactions of these nano-conjugates will indicate the topoisomerase potential in line with the observed aPDT activity, while the ADMETlab online tool toxicological simulations will indicate the possible toxicological impacts, for further investigation.

\section{MATERIALS AND METHODS}

Reagents were purchased from Sigma-Aldrich (Steinem, Germany). The chemicals were used without any purifications except the pyrrole which was distilled before use. The bacterial strains used for this study included the Gram-positive bacteria, E. faecalis (ATCC\#29212), S. aureus (ATCC\# 25925) and the Gram-negative bacteria K. pneumonia (ATCC\#4352) obtained from the microbiology culture bank at the University of Zululand where all the microbiological tests were carried out. A detailed description of the synthesis of the two porphyrins; TPyP and TAP, their encapsulation and characterizations are given below.

\section{Synthesis of 5,10,15,20-tetrakis(4-pyridyl)porphyrin (TPyP)}

The preparation was conducted as described in the literature using the Adler method (33) with modifications. A mixture of pyridine carboxaldehyde $(4.71 \mathrm{ml}, 50.0 \mathrm{mmol})$ and acetic anhydride $(6.50 \mathrm{ml}$, $68.8 \mathrm{mmol}$ ) was dissolved in $50 \mathrm{ml}$ propionic acid and freshly distilled pyrrole $(3.24 \mathrm{ml}, 50.0 \mathrm{mmol})$ in $10 \mathrm{ml}$ propionic acid and added dropwise while refluxing under $\mathrm{N}_{2}$ atmosphere for 2-4 hours. The reaction mixture was allowed to cool down overnight in open air and propionic acid was removed by distillation at $141{ }^{\circ} \mathrm{C}$ obtaining dark purple precipitate. The precipitate was washed with hot water followed by the neutralization with aqueous ammonia and further washed with hot water to obtain a purple solid. The purple solid was further treated with dichloromethane, followed by vacuum filtration obtaining TPyP which was dissolved in chloroform and purified by column chromatography using chloroform, hexane and methanol as an eluent to obtain purple crystals ${ }^{34}$. Yield 2.2g (22\%). IR ( $\left.\mathrm{cm}^{-1}\right) ; 3372,883,760,1209,2972$. UVVis $\left(\lambda_{\text {max }}: \mathrm{nm}, \mathrm{CHCl}_{3}\right) ; 412,512,543,587,649 .{ }^{1} \mathrm{HNMR}\left(\delta_{\mathrm{ppm}}: \mathrm{CDCl}_{3}\right)$; $9.09(\mathrm{~d}, J 8.87 \mathrm{~Hz}, 8 \mathrm{H}), 8.89(\mathrm{~s}, J 8.65 \mathrm{HZ} 8 \mathrm{H}), 8.19(\mathrm{~d}, 8 \mathrm{H}),-2.90(\mathrm{~s}, 2 \mathrm{H}$,$) .$ $\mathrm{CHN}$ (\%); C, 78.10, H, 6.04, N, 15.85. The data compared well with the literature ${ }^{35}$.

\section{Synthesis of 5,10,15,20-tetrakis(4-nitrophenyl)porphyrin}

5,10,15,20-tetrakis(p-nitrophenyl)porphyrin (TAP) was synthesised using the Lindsey reaction as in literature. $P$-nitro benzaldehyde (34 mmol, $5.26 \mathrm{~g})$ and acetic anhydride $(64 \mathrm{mmol}, 6 \mathrm{ml})$ was added to $50 \mathrm{ml}$ propionic acid while stirring under a nitrogen atmosphere and the resulting solution was heated to reflux. Freshly distilled pyrrole $(34 \mathrm{mmol}, 11.5 \mathrm{ml})$ in $10 \mathrm{ml}$ propionic acid was added to the refluxing solution and allowed to reflux for a further 30 minutes while stirring. The resulting reaction mixture was allowed to cool to room temperature and for a further 24 hours in open air. The black solution was filtered under vacuum and a black tarry powder was obtained. The black tarry powder was transferred to a $150 \mathrm{~mL}$ round-bottomed flask, $40 \mathrm{ml}$ of pyridine was added and the mixture was refluxed for an hour. The mixture was cooled to room temperature and further cooled at -40
${ }^{0} \mathrm{C}$ for 24 hours. The tarry liquid was filtered and washed with acetone until the rinsing was no longer dark to yield 5,10,15,20-tetrakis(4nitrophenyl)porphyrin.

\section{Synthesis of 5,10,15,20-tetrakis(4-aminophenyl)porphyrin (TAP)}

5,10,15,20-tetrakis(nitrophenyl)porphyrin ( $2.5 \mathrm{mmol}, 2 \mathrm{~g}$ ) was bubbled for one hour in $100 \mathrm{ml} \mathrm{HCl}(0.1 \mathrm{M})$ with $\mathrm{N}_{2}$. Stannic chloride hydrate $\left(\mathrm{SnCl}_{2} . \mathrm{H}_{2} \mathrm{O}: 9.0128 \mathrm{~g}, 40 \mathrm{mmol}\right)$ in $10 \mathrm{ml} \mathrm{HCl}(0.1 \mathrm{M})$ was bubbled with $\mathrm{N}_{2}$ and added to the solution. The resulting mixture was then heated in a water bath at $78^{\circ} \mathrm{C}$ for 30 minutes and then slowly transferred to a coldwater bath and an ice bath at $-4{ }^{\circ} \mathrm{C}$. Aqueous sodium hydroxide $(0.1 \mathrm{M})$ was added to the reaction mixture to neutralize the solution under cold temperatures. The solution was then filtered to obtain a greenish solid which was stirred vigorously with sodium hydroxide (200 ml: $0.1 \mathrm{M})$. The resulting solid was then filtered, dried and purified using a Soxhlet extractor in chloroform to give purple crystals. Yield (1.97 g, (21\%). IR $\left(\mathrm{cm}^{-1} \mathrm{CHCl}_{3}\right) ; 2976,1211,748,664$. UV-Vis $\left(\lambda \max , \mathrm{nm}, \mathrm{CHCl}_{3}\right) ; 427$, 526, 565, 598, 660. ${ }^{1} \mathrm{HNMR}\left(\delta \mathrm{ppm} \mathrm{CDCl}_{3}\right) ; 8.87$ (s, J 8.87Hz, 8H), 8.26 (d, 8H, J 8.90HZ), 7.05 (dd, $8 \mathrm{H} J 7.76 \mathrm{HZ}$ ), -2.75 (s, 2H) CHN (\%); C, $76.69, \mathrm{H}, 7.275, \mathrm{~N}, 16.02$. The data coincides with literature ${ }^{36}$.

\section{Resuscitation of Microorganisms}

The bacteria selected were inoculated in a nutrient broth and incubated at $37^{\circ} \mathrm{C}$ overnight. Following this, $1.0 \mathrm{ml}$ of the bacteria in the nutrient broth was then pipetted in $9 \mathrm{ml}$ freshly prepared nutrient broth placed in separate test tubes labelled with corresponding microorganisms. The test tubes were also incubated overnight at $37^{\circ} \mathrm{C}$. The next step was to read the absorbance of the selected bacterial strains on the spectrophotometer at $600 \mathrm{~nm}$ to determine their turbidity. The turbid resulting suspensions were diluted with nutrient broth to obtain an absorbance of $0.132 \mathrm{~nm}$ which is comparable to that of the 0.5 McFarland turbidity standard taken to consist of $1.5 \times 10^{-3}$ colony forming units (CFU)/ml ${ }^{37}$.

\section{ANTI-BACTERIAL ACTIVITY}

\section{Minimum Inhibitory Concentration (MIC)}

The test compounds were investigated for antibacterial activity against S. aureus (ATCC 25925), E. faecalis (ATCC 29212) and K. pneumoniae (ATCC 4352) using the micro-dilution method. Mueller Hinton broth $(\mathrm{MH})(100 \mu \mathrm{l})$ was pipetted into each of the wells of a 96-well micro-plate. The test compounds were then added into the first row of the micro-plate and serially diluted to a range between 50 and $0.313 \mathrm{mg} / \mathrm{ml}$. Thereafter, $100 \mu \mathrm{l}$ of the fresh bacterial cultures at a density of $1 \times 10^{6} \mathrm{CFU} \cdot \mathrm{ml}^{-1}$, was pipetted into the wells. DMSO (10\%) was used as negative control while ciprofloxacin $(20 \mu \mathrm{g} / \mathrm{ml})$ served as a positive control. The micro-plates were sealed and incubated at $37^{\circ} \mathrm{C}$ overnight. Afterwards, p-iodonitro tetrazolium violet solution (INT: $40 \mu \mathrm{l}$ of a $0.2 \mathrm{mg} / \mathrm{ml}$ solution) was added to each of the wells and the micro-well plate was incubated at $37^{\circ} \mathrm{C}$ for 30 minutes. The MIC was perceived as the lowest concentration of the test compounds to inhibit bacterial growth ${ }^{38}$. Figure 2 shows a simplified procedure for the determination of the MIC and the MBC.

\section{Minimum Bactericidal Concentration (MBC)}

MBC of the test compounds was assessed by removing a loopful of each culture from the wells that had no bacterial growth and streaking it on sterile $\mathrm{MH}$ agar plates. The agar plates were incubated at $37^{\circ} \mathrm{C}$ for 24 hours. The lowest concentration of the test compounds that exhibited the complete killing of the tested bacterial strains was considered as the $\mathrm{MBC}^{39}$. 

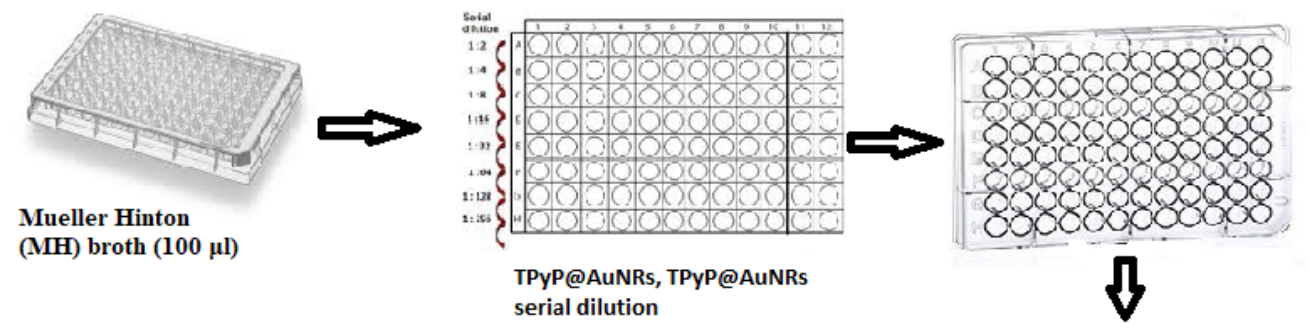

S. aureus (ATCC

25925), E. faecalis (ATCC 29212) and $K$. pneumoniae (ATCC 4352)
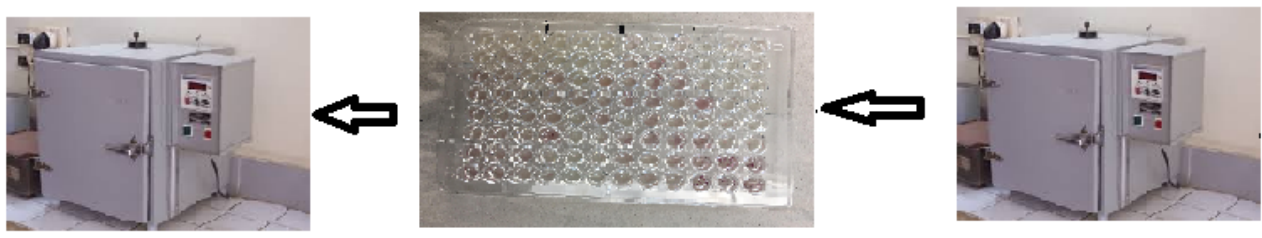

Incubation at $37^{\circ}$ C overnight

Incubation at $37^{\circ}$

Addition of p-iodonitro

C for $\mathbf{3 0}$ minutes

tetrazolium violet solution (INT:

$40 \mu \mathrm{l}$ of $0.2 \mathrm{mg} / \mathrm{ml}$ )

Figure 2: Schematic representation of the evaluation of MIC and MBC of the compounds.

\section{RESULTS AND DISCUSSION}

Synthesis of TPYP and TAP

\section{UV/Vis Spectroscopy}

Synthesis of TAP and TPyP was studied using the Ultraviolet and Visible spectroscopy (UV-Vis). The spectrum of TPyP and TAP show two band sets; one Soret band and four $\mathrm{Q}$ bands. The soret band appears at $512 \mathrm{~nm}$ while the Q bands are at 412, 512, 546, 586 and $645 \mathrm{~nm}$ for TPyP and $427,526,565,598$, and $660 \mathrm{~nm}$ for TAP. The shape of the bands is of phyllo type due to the amino-phenyl groups attached at meso positions.

\section{FTIR Spectroscopy}

The FTIR spectrum of TPyP synthesized at different times is in total agreement with the structure. Absorptions at 3372 and $883 \mathrm{~cm}^{-1}$ are a result of the stretching and bending vibrations of $\mathrm{N}-\mathrm{H}$ and $\mathrm{C}-\mathrm{N}$ respectively, this is a characteristic of a free base porphyrin. The intense band that is observed at $760 \mathrm{~cm}^{-1}$ is attributed to the $\mathrm{C}-\mathrm{H}$ bond from the pyrrolic ring. At $671 \mathrm{~cm}^{-1}$, the band observed is of the $\mathrm{C}-\mathrm{H} \mathrm{sp}{ }^{2}$. At $1209 \mathrm{~cm}^{-1}$ there is a band that signifies the $\mathrm{N}-\mathrm{H}$ out of phase bending while the $2972 \mathrm{~cm}^{-1}$ signifies one of the $\mathrm{C}-\mathrm{H}$ pyrrolic rings, $\mathrm{sp}^{3}$. The functional groups of TAP were confirmed and studied using a Fourier Transform Infrared Spectrometer. The spectrum obtained for the TAP was in agreement with the expected structure. The band at $748 \mathrm{~cm}^{-1}$ is a result of $\mathrm{C}-\mathrm{N}$ stretching and bending vibrations characteristic of the free-base porphyrins. The band at $2976^{-1}$ is the N-H out of phase and is more significant in the porphyrin synthesized in an ionic liquid than in propionic acid.

\section{NMR Spectroscopy}

The structure of TPyP was confirmed using ${ }^{1} \mathrm{H} 600 \mathrm{MHz}$ NMR spectroscopy. At $8.87 \mathrm{ppm}$ lies a doublet from the two $\beta$ protons. The singlet at $8.89 \mathrm{ppm}$ is attributed to the 8 protons meta to $\mathrm{N}$ on the pyridyl ring. The doublet at $8.19 \mathrm{ppm}$ is due to the protons ortho the $\mathrm{N}$ in the pyridyl ring. Lastly, at $-2.90 \mathrm{ppm}$ a singlet is observed attributed to the protons on the $\mathrm{NH}$ on the interior of the porphyrin ring. The confirmation of the structure of TAP was done using ${ }^{1} \mathrm{H} 600 \mathrm{MHz}$ NMR spectroscopy. The peaks coincided well with the structure. The singlet at $8.87 \mathrm{ppm}$ is due to the $\beta$ pyrrole protons. At $8.26 \mathrm{ppm}$, a doublet is seen attributed to the 8 protons meta to the $\mathrm{NH}_{2}$. The doublet of doublets at
$7.05 \mathrm{ppm}$ is due to the 8 protons ortho to $\mathrm{NH}_{2}$. The signal at $-2.75 \mathrm{ppm}$ is attributed to the protons at the $\mathrm{NH}$ on the interior of the porphyrin ring.

\section{Elemental analysis}

CHNS analysis, TPyP. (\%); Theoretical data for $\mathrm{C}_{40} \mathrm{H}_{26} \mathrm{~N}_{8} ; \mathrm{C}, 78.30, \mathrm{H}$, 6.45, N, 16.61. Experimental; C, 78.10, H, 6.04, N, 15.85. CHNS analysis TAP, (\%); Theoretical data for $\mathrm{C}_{44} \mathrm{H}_{34} \mathrm{~N}_{8}$; C, 78.32, H, 5.08, N, 16.61 . Experimental; C, 76.69, H, 7.275, N, 16.02. Except for a slightly higher measured hydrogen content of TAP, the calculated and measured values were in close agreement. The slightly higher measured hydrogen content of TAP is attributed to the hydrogenation of the amino groups of the isolated TAP.

\section{Antibacterial evaluation}

The microdilution method was used to investigate the minimum inhibition concentration (MIC) of the test compounds. The test compounds showed broad-spectrum activity against all tested bacterial strains. The minimum inhibitory concentration of the test compounds ranged from $0.78 \mathrm{mg} / \mathrm{ml}$ to $2.60 \mathrm{mg} / \mathrm{ml}$ for TPyP-AuNRs and $0.42-1.8 \mathrm{mg} / \mathrm{ml}$ for TAP-AuNRs as in Table 1 . The effect of the test compounds was more pronounced against Gram-positive bacterial strains than Gram-negative strains. Cationic porphyrins effectively interact with the cell walls of Gram-negative and positive and hence they photo inactivate the bacteria. A direct mechanism is not known for the interaction but the porphyrins are found to undergo Type 1 and Type II photosensitization ${ }^{40}$. Gram-negative bacteria (K. pneumoniae) were resistant to lower concentrations of the test material $(x<50 \mathrm{mg} / \mathrm{ml})$. This could be attributed to the thin peptidoglycan layer of the outer membrane as seen in Figure 3. This outer membrane consists of an additional protective lipopolysaccharide layer that exhibits resistance and antigenicity against antibacterial agents and hence a conclusion was drawn that the high resistance of $K$. pneumoniae is due to this layer. The antibacterial activity of the test materials was due to the abiotic and biotic elicitation. Because porphyrins can inhibit the growth of the micro-organism, the highest concentration gives the best results $(50 \mathrm{mg} / \mathrm{ml})$.

Generally, bacterial growth is composed of peptones (peptides and amino acids) and these are obtained through the hydrolysis of natural products or enzymatic digestion. The products can sometimes induce 


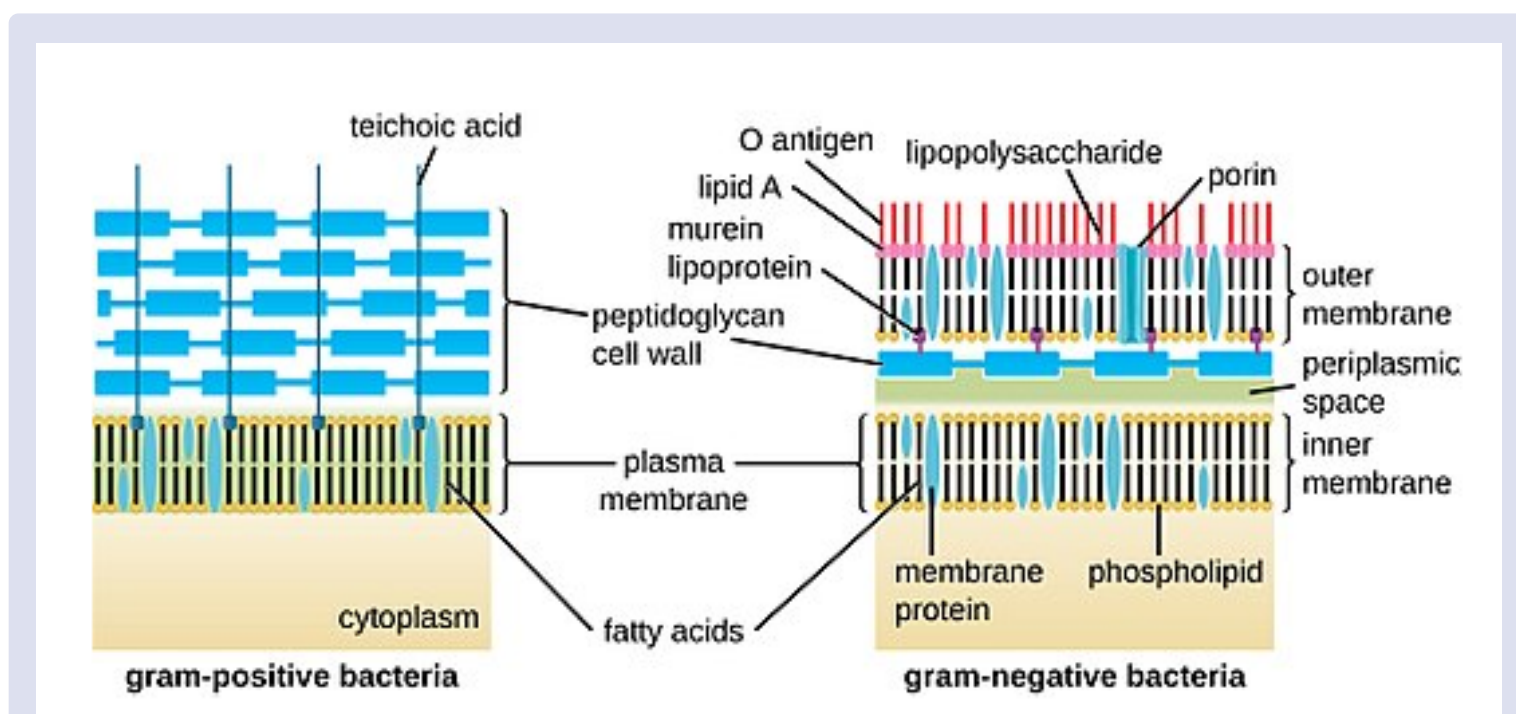

Figure 3: Schematic diagram of the cell wall of Gram (+) bacteria left, and Gram (-) bacteria (right).

Table 1: MIC and MBC of TPyP, TAP, and Ciprofloxacin against K. pneumonia (ATCC 4352), S. aureus (ATCC 25925), and E. faecalis.

\begin{tabular}{lcccc}
\hline Isolate & MIC/MBC & K. pneumonia & S. aureus & E. faecalis \\
TPyP & MIC $(\mathrm{mg} / \mathrm{ml})$ & $2.6 \pm 0.7$ & $0.78 \pm 0.0$ & $1.5 \pm 0.0$ \\
& $\mathrm{MBC}(\mathrm{mg} / \mathrm{ml})$ & $>50 \pm 0$ & $>50 \pm 0$ & $>50 \pm 0$ \\
TAP & $\mathrm{MIC}(\mathrm{mg} / \mathrm{ml})$ & $1.8 \pm 0.6$ & $0.42 \pm 0.1$ & $0.76 \pm 0.0$ \\
& $\mathrm{MBC}(\mathrm{mg} / \mathrm{ml})$ & $>50 \pm 0$ & $3.13 \pm 0.0$ & $>50 \pm 0$ \\
Ciprofloxacin & $\mathrm{MIC}(\mathrm{mg} / \mathrm{ml})$ & $3.13 \pm 0.0$ & $6.25 \pm 0.0$ & $14.6 \pm 6.0$ \\
& $\mathrm{MBC}(\mathrm{mg} / \mathrm{ml})$ & $12.5 \pm 0.0$ & $0.52 \pm 0.0$ & $12.5 \pm 0.0$ \\
AuNRs- PEG & $\mathrm{MIC}(\mathrm{mg} / \mathrm{ml})$ & $1.7 \pm 0.3$ & $>50 \pm 0$ & $0.68 \pm 0.0$
\end{tabular}

the aggregation of the AuNPs. The use of PEG however enhanced the disaggregation and stability of the AuNRs and also prevents nonspecific protein adsorption. MIC and MBC values of the test materials consisting of AuNRs capped with porphyrin containing PEG confirmed the bacteriostatic properties but not the bactericidal properties of the materials against the bacterial strains. Capping off the AuNRs with PEG and porphyrins reduces the aggregation of the particles. Furthermore, this enhances the particles to be more compatible with the biological media and this is due to the reduced non-specific protein absorption, and the biocompatibility of the PEG outer shell.

This means that the higher the concentration, the higher the bacterial inhibition. Thus, our test materials have moderate to weak antibacterial activity. The test materials did not show any bactericidal effect against the tested strains (Table 1). The imposition of antibacterial materials on exponentially growing bacterial strains is either bactericidal, bacteriostatic or bacteriolytic. In the absence of light, therefore, the test compounds used, possess only the bacteriostatic effect and not the bactericidal effect against the tested strains as shown by the MIC and MBC data shown in Table 1.

\section{DOCKING STUDIES}

\section{Preparation of Ligands}

The three-dimensional (3D) structures of the two ligands and the control (ciprofloxacin) were procured from the ChemSpider compound database. The compounds were downloaded in StructureData File (SDF) format and converted to PDB coordinates using Biovia
Discovery Studio 4.1 visualizer. They were then loaded to AutoDock Vina and converted to PDBQT files ${ }^{41}$.

\section{Receptor preparation}

The 3D structures of the receptor protein DNA gyrase (PDB ID: 5Z9N) were obtained from the Protein Data bank (www.rcsb.org). DNA gyrase is responsible for DNA replication. Thus, DNA gyrase is one of the main targets during the process of discovery and development of antibacterial agents ${ }^{42}$. The receptor protein was loaded into the Biovia Discovery Studio 4.1 Visualizer. All the water molecules, heteroatoms and other ligands were removed from the crystal structure. Thereafter, the polar hydrogen was added (50). The prepared receptor was then loaded into AutoDock Vina in the PDB file and then converted to the PDBQT file to enable the docking process ${ }^{41}$.

\section{Docking}

The ligands were docked to DNA gyrase subunit A (PDB code: $5 \mathrm{Z9N}$ ) using AutoDock Vina ${ }^{41}$. The docking simulations between the ligands and the receptor protease were performed by using the AutoDock Vina. The docking was feasible within the binding sphere with the centre $\mathrm{x}$ $=-35.279000$, centre $\mathrm{y}=-5.820250$, centre $\mathrm{z}=-21.159417$, size $\mathrm{x}=40$, size $y=40$, size $z=40$ and exhaustiveness $=8$. A maximum of nine conformers was considered the ligand-receptor complexes. The lowest binding energy $(\mathrm{kcal} / \mathrm{mol})$ of the docked ligand-receptor complexes were taken as the best-docked conformations. The Discovery Studio visualizer 4.1 was used to visualise the interactions of the docked complexes and to deduce the $3 \mathrm{D}$ and $2 \mathrm{D}$ pictorial representations of the interactions (50). 


\section{Pharmacokinetic properties}

The SwissADME online tool was used to assess the pharmacokinetic properties of the compounds. The simplified molecular-input line-entry system (SMILES) for each compound were procured from PubChem and incorporated into the SwissADME online tool. Thereafter, the ADME properties that include absorption: gastrointestinal absorption (GA), distribution: blood-brain barrier (BBB) permeability, metabolism: isomers of cytochrome P450 (CYP) inhibitors, excretion: P-glycoprotein (P-gp) substrate were computed ${ }^{43}$.

\section{Toxicological study of the compounds}

The toxicological properties of the two porphyrin compounds were investigated using the online server ADMETlab online tool. The SMILES of the compounds were obtained from PubChem and inserted into the ADMETlab online tool. Thereafter, each compound was evaluated for its potential to inhibit the human ether-a-go-go-related (hERG) gene and for its human hepatotoxicity (HHT) and mutagenicity ${ }^{44}$.

Molecular docking is a computational tool primarily used to predict the structural orientations, binding affinities and receptor-ligand interactions ${ }^{45}$. To understand the mechanism of antibacterial activity of the ligands, AutoDock Vina was employed to predict the strength of binding affinity between the receptor protein and ligands using scoring functions and the results are displayed in Table 2. TPyP has a binding free energy of $-8.7 \mathrm{kcal} / \mathrm{mol}$ whereas TAP has a binding free energy of $-8.3 \mathrm{kcal} / \mathrm{mol}$. It was also noted that both ligands have binding free energies lower than that of the control, ciprofloxacin $(-6.9 \mathrm{kcal} / \mathrm{mol})$. Receptor-ligand interactions occur spontaneously when the free energy change is negative; the negative energy values indicate the stability of the receptor-ligand complexes and the lower the binding free energy, the better the binding affinity ${ }^{41}$. The compounds showed better binding values than the control and the results correlate with those obtained from in vitro antibacterial activity.

The free binding energy values of the receptor-ligand complexes are due to various types of molecular bonds formed. The molecular receptorligand interactions at the active site of DNA gyrase are summarized in Table 2, Figure 4 and 5. TPyP formed conventional hydrogen bonds with amino acid residues GLN A:72 and LYS A:162, pi-cation with
LYS A:208, GLN A:72 and LYS A:162 and pi-alkyl with ILE A:60 of the receptor protein. The other interactions observed are van der Waals and unfavourable donor-donor bonds. TAP had hydrogen bonds with ASP A:49, pi-donor hydrogen bonds with amino acid residues LEU A:52 and HIS A:55 and pi sigma with ALA A:51. Other interactions were van der Waals bonds. Ciprofloxacin had four hydrogen bonds with VAL A:120, SER A:121 and ILE A:94. The binding forces formed are van der Waals forces, pi-sigma bonds, alkyl and pi-alkyl bonds. It was thus concluded that the ligands interact strongly with the functional groups of the DNA gyrase, suggesting potential for bacterial DNA gyrase based photodynamic inactivation. Given the topoisomerase role of the bacterial DNA gyrase enzyme, the results of these docking studies suggest that the mechanism of the demonstrated bacterial inactivation by TPyP and TAP might involve abolishing the activity of the bacterial DNA gyrase enzyme by a photodynamic mechanism.

\section{Pharmacokinetic properties of the compounds}

To be considered ideal for use as antimicrobial agents, test compounds should show high efficacy coupled with desirable pharmacokinetic properties. SwissADME online tool was used to assess the pharmacokinetic properties of the compounds. The results of the SwissADME online tool modelling studies of the pharmacokinetic properties of the test compounds are summarized in Tables 3. GA is the level of the absorption of the orally administered test compounds from the gastrointestinal tract into the bloodstream ${ }^{46}$. TPyP showed a high potential to be absorbed in the gastrointestinal tract whereas TAP demonstrated lower potential (Table 3). GA greatly influences the bioavailability of the orally taken compounds ${ }^{45}$. Thus, only TPyP is likely to be bioavailable in the body system upon oral administration, whereas TAP is likely to be poorly delivered systemically via oral administration. For these reasons, it might be more feasible to opt for the intravenous injection method for both compounds.

The blood-brain barrier (BBB) is an important factor for test compounds that target the brain cells. However, if the compounds are not targeting brain cells, their inability to cross BBB is of an advantage as they cannot induce any adverse side effects in the brain ${ }^{47}$. The ability for the compounds to penetrate through BBB was predicted and the results are shown in Table 3 . Both compounds did not show the potential to cross

Table 2: The binding energy $(\mathrm{kcal} / \mathrm{mol})$ of the receptor-ligand complexes.

\begin{tabular}{cccc}
\hline Compounds & Binding energy & H-bonds interaction residues & $\begin{array}{c}\text { Number of other interacting } \\
\text { residues }\end{array}$ \\
\hline TPyP & -8.7 & GLN A:72 and LYS A:162 & 10 \\
TAP & -8.3 & ASP A:49 and HIS A:55 & 10 \\
Ciprofloxacin & -6.9 & VAL A:120, SER A:121 and ILE A:94 & 10
\end{tabular}

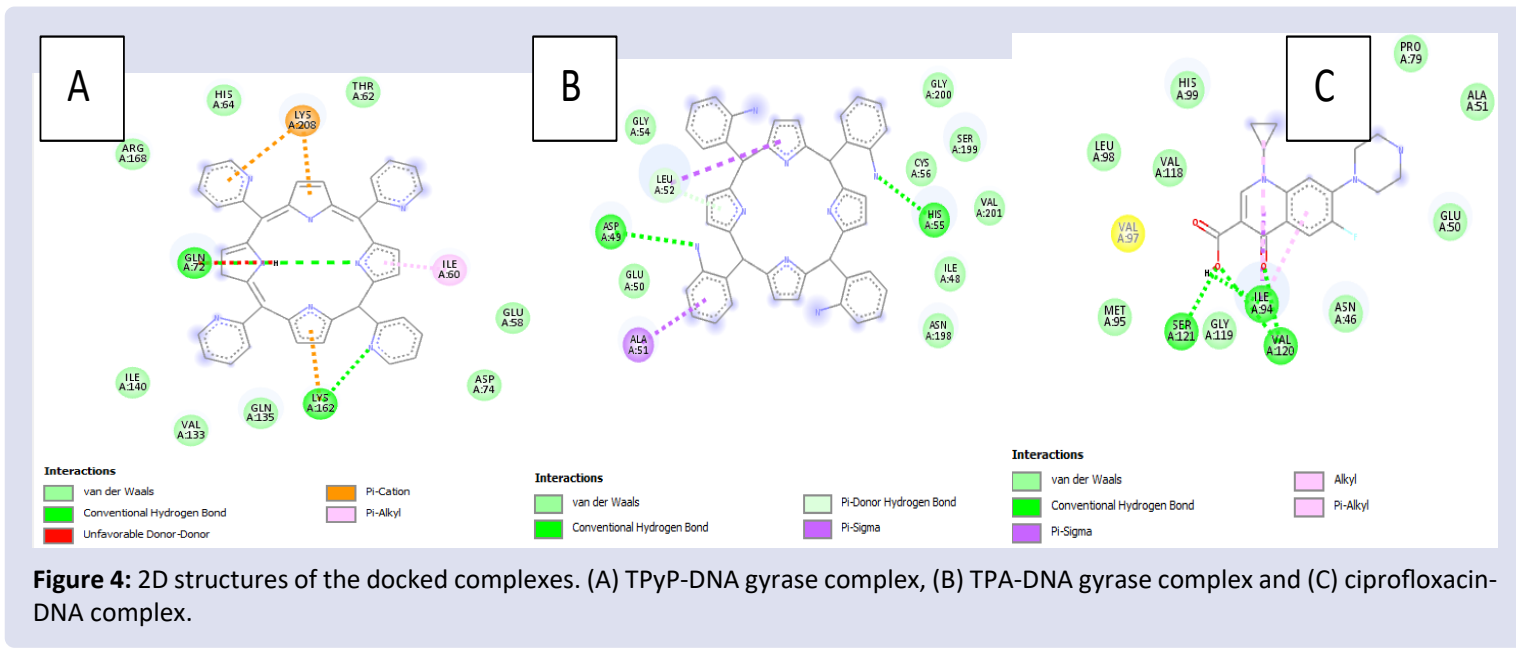




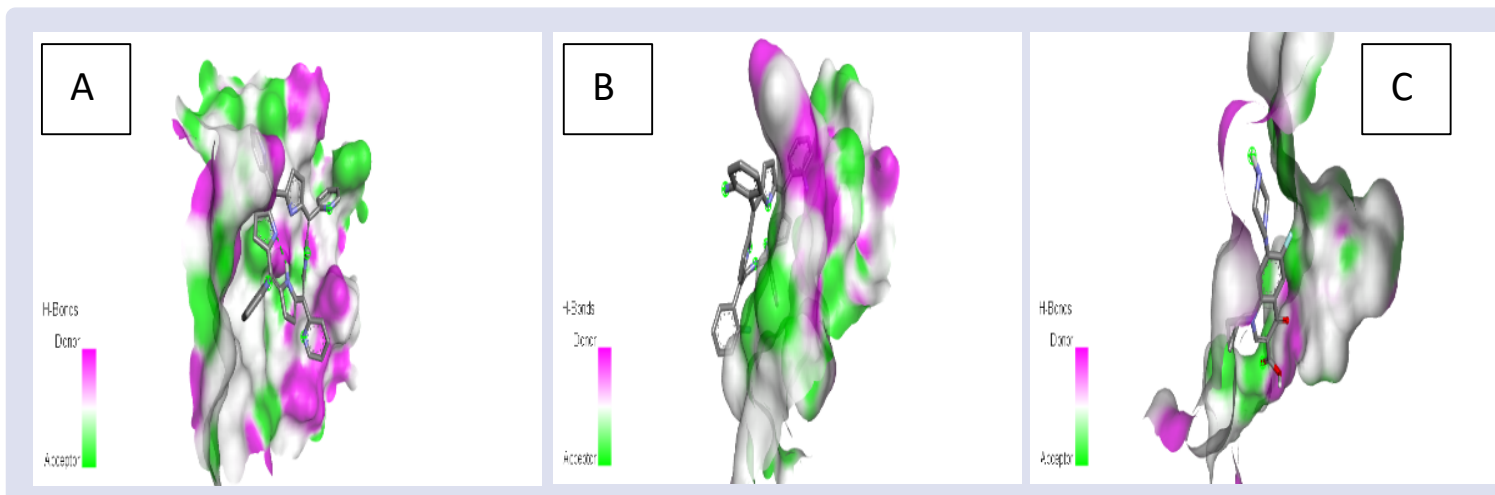

Figure 5: The 3D structures of the docked ligands inside the binding pocket of the receptor. (A) TPyP-DNA gyrase complex, (B) TPADNA gyrase complex and (C) ciprofloxacin-DNA gyrase complex.

Table 3: The pharmacokinetic properties of the compounds.

\begin{tabular}{ccc}
\hline Compounds & TPyP & TAP \\
\hline GA & High & Low \\
BBB Permeate & No & No \\
P-gp substrate & Yes & Yes \\
CYP 1A2 inhibitor & Yes & Yes \\
CYP 2C19 inhibitor & No & No \\
CYP 2C9 inhibitor & No & No \\
CYP 2D6 inhibitor & No & No \\
CYP 3A4 inhibitor & Yes & No
\end{tabular}

Table 4: The predicted toxicology study of the compounds.

\begin{tabular}{|c|c|c|c|}
\hline \multirow{2}{*}{ Compounds } & \multicolumn{3}{|c|}{ Toxicity } \\
\hline & hERG inhibition & HHT & Mutagenicity \\
\hline TPyP & Positive & Negative & Positive \\
\hline
\end{tabular}

BBB. The results are indicative of the inability of these compounds to be used to treat brain-related disorders and potential biosafety, as they cannot induce adverse side effects in brain cells. The broad substrate specificity ATP-dependent efflux pump P-gp plays a vital role in the trans-membrane transportation of molecules. The efflux action of P-gp tends to resist drug efficacies in the cells as it pumps the administered drugs out of the cells, consequently lowering their concentrations and effectiveness ${ }^{48}$. The test compounds are predicted to be the substrates of P-gp (Table 3). This implies that their pharmacological activities can be compromised by the efflux action of P-gp, clearing the cell interior and therefore forcing their activity to be on the outer cell wall. Cytochrome P450 (CYP) are heme-proteins found in the liver and are the major drug metabolising proteins. They are responsible for the metabolism of more than $75 \%$ of the currently available drugs in the market ${ }^{49}$. The computed effect of the compounds on the five major CYP isoforms (CYP 1A2, CYP 2C19, CYP 2C9, CYP 2D6 and CYP 3A4) are shown in Table 3. Out of the five CYP isomers, TPyP showed the ability to inhibit CYP $1 \mathrm{~A} 2$ and CYP 3A4 whereas TAP was predicted to only inhibit CYP 1A2. The blockage of CYP isoforms translates to biodegradation and bioavailability reduction of the compounds. Moreover, the accumulation of compounds due to the inability to be metabolised can lead to adverse toxicological outcomes ${ }^{50}$. Nevertheless, the majority of the tested isoforms were not inhibited by TPyP or TAP, thus increasing their bioavailability.

\section{Toxicity studies of the compounds}

The majority of pharmacologically active compounds often fail in the last stages of drug discovery and development due to toxic effects such as cardiotoxicity (hERG inhibition), hepatotoxicity and mutagenicity.
The hERG is the gene in the heart muscle that encodes for the voltagegated potassium channel, which is responsible for the formation of the cardiac activity potential. It simply regulates the heartbeat by controlling the potassium current (IKr). Thus, the hERG inhibitors tend to induce cardiac arrhythmia and sudden death ${ }^{45}$. The effect of the compounds on hERG was evaluated and the results are shown in Table 3. Both compounds were found to have the potential to inhibit hERG. This implies that these compounds fall in the category of drugs like terfenadine and astemizole, which can induce prolonged QT-interval and heart failure ${ }^{51}$.

The human liver is the main site for drug metabolism. This means that it is highly vulnerable to the harmful effects of xenobiotic agents and drugs. Human hepatotoxicity (HHT) includes any form of injury to the liver that may result in organ failure ${ }^{51}$. The HHT of the compounds were predicted and the results are illustrated in Table 4 . The compounds displayed no human hepatotoxic effects. This implies that the compounds cannot induce any impairment in the liver and cannot temper with its functions. Ames test is used to evaluate the potential mutagenicity of compounds. The mutagenic compounds can cause mutations in the genes and cause cancerous cells ${ }^{52}$. The mutagenic effects of the compounds are shown in Table 4 . The compounds showed the potential to induce mutagenic effects in humans. This means the compounds pose a great threat to human health as they have the potential to generate cancer cells in the body.

\section{CONCLUSION}

Many authors consider the antimicrobial activities to be significant if the MIC value is $0.1 \mathrm{mg} / \mathrm{ml}$ or lower, moderate if $0.1<$ MIC $\leq 0.625$ $\mathrm{mg} / \mathrm{ml}$ and weak if MIC $>0.625 \mathrm{mg} / \mathrm{ml}^{38,53}$. Although the porphyrin 
compounds did not show bactericidal effects but only bacteriostatic, they can be used as potential agents against bacterial infections and tumours. TPyP had binding free energy of $-8.7 \mathrm{kcal} / \mathrm{mol}$ whereas TPA had binding free energy of $-8.3 \mathrm{kcal} / \mathrm{mol}$. They showed promising pharmacokinetic properties. Both compounds have the potential to cause cardiotoxic and mutagenic effects but not hepatotoxic effects. These findings suggest that the porphyrins TPYP and TAP could be investigated further as agents for the combination of photodynamic therapy and photothermal therapy, to establish whether there is an enhancement of their anticancer and antibacterial activity because such additive and/or synergistic enhancement would mean that the effective therapeutic doses would be much less than the MIC and MBC range observed in this study. Pharmacokinetic studies suggest that it might be more feasible to opt for the intravenous injection method for both materials.

\section{ACKNOWLEDGEMENTS}

The authors would like to appreciate the National Research Foundation of South Africa, the University of Zululand and the University of KwaZulu Natal for providing financial support and laboratory facilities.

\section{CONFLICTS OF INTEREST}

The authors declare no conflicts of interest.

\section{REFERENCES}

1. O'Brien KL, Wolfson LJ, Watt JP, et al. Burden of disease caused by Streptococcus pneumoniae in children younger than 5 years: global estimates. Lancet. 2009;374(9693):893-902. doi:10.1016/ S0140-6736(09)61204-6

2. Greenfield RA, Bronze MS. Prevention and treatment of bacterial diseases caused by bacterial bioterrorism threat agents. Drug Discov Today. 2003;8(19):881-888. doi:10.1016/S1359-6446(03)02847-2

3. Shandu JS, Manqele A, Maliehe TS, Shode FO. Comparative evaluation of antibacterial activity of induced and non-induced Cajanus cajan seed extract against selected gastrointestinal tract bacteria. African J Microbiol Res. 2016;10(10):319-323. doi:10.5897/ ajmr2015.7817

4. Davey PG, Marwick C, Centre HI. REVIEW Appropriate vs. inappropriate antimicrobial therapy. Microbiology. 2008;14:15-21.

5. Kaye KS, Engemann JJ, Fraimow HS, Abrutyn E. Pathogens resistant to antimicrobial agents: Epidemiology, molecular mechanisms, and clinical management. Infect Dis Clin North Am. 2004;18(3):467-511. doi:10.1016/j.idc.2004.04.003

6. Sambanthamoorthy K, Feng X, Patel R, Patel S, Paranavitana C. Antimicrobial and antibiofilm potential of biosurfactants isolated from lactobacilli against multi-drug-resistant pathogens. BMC Microbiol. 2014;14(1):1-9. doi:10.1186/1471-2180-14-197

7. Powers JH. Development of drugs for antimicrobial-resistant pathogens. Curr Opin Infect Dis. 2003;16(6):547-551. doi:10.1097/00001432-200312000-00006

8. Sievert DM, Ricks P, Edwards JR, et al. Antimicrobial-Resistant Pathogens Associated with Healthcare-Associated Infections Summary of Data Reported to the National Healthcare Safety Network at the Centers for Disease Control and Prevention, 2009-2010. Infect Control Hosp Epidemiol. 2013;34(1):1-14. doi:10.1086/668770

9. Rajesh S, Koshi E, Philip K, Mohan A. Antimicrobial photodynamic therapy: An overview. J Indian Soc Periodontol. 2011;15(4):323327. doi:10.4103/0972-124X.92563

10. Garcez AS, Ribeiro MS, Tegos GP, Núñez SC, Jorge AOC, Hamblin MR. Antimicrobial photodynamic therapy combined with conventional endodontic treatment to eliminate root canal biofilm infection. Lasers Surg Med. 2007;39(1):59-66. doi:10.1002/ Ism. 20415
11. de Oliveira RR, Schwartz-Filho HO, Novaes AB, Taba M. Antimicrobial Photodynamic Therapy in the Non-Surgical Treatment of Aggressive Periodontitis: A Preliminary Randomized Controlled Clinical Study. J Periodontol. 2007;78(6):965-973. doi:10.1902/ jop.2007.060494

12. Cormick MP, Alvarez MG, Rovera M, Durantini EN. Photodynamic inactivation of Candida albicans sensitized by tri- and tetra-cationic porphyrin derivatives. Eur J Med Chem. Published online 2009. doi:10.1016/j.ejmech.2008.07.026

13. Cormick MP, Alvarez MG, Rovera M, Durantini EN. Photodynamic inactivation of Candida albicans sensitized by tri- and tetra-cationic porphyrin derivatives. Eur J Med Chem. 2009;44(4):1592-1599. doi:10.1016/j.ejmech.2008.07.026

14. Merchat M, Spikes JD, Bertoloni G, Jori G. Studies on the mechanism of bacteria photosensitization by meso-substituted cationic porphyrins. J Photochem Photobiol B Biol. 1996;35(3):149157. doi:10.1016/S1011-1344(96)07321-6

15. Fiel RJ. Porphyrin- nucleic acid interactions: A review. J Biomol Struct Dyn. 1989;6(6):1259-1274. doi:10.1080/07391102.1989.10 506549

16. Pasternack RF, Gibbs EJ, Gaudemer A, et al. Molecular Complexes of Nucleosides and Nucleotides with a Monomeric Cationic Porphyrin and Some of Its Metal Derivatives. J Am Chem Soc. 1985;107(26):8179-8186. doi:10.1021/ja00312a061

17. Simões AVC, Adamowicz A, Dabrowski JM, et al. Amphiphilic meso(sulfonate ester fluoroaryl)porphyrins: Refining the substituents of porphyrin derivatives for phototherapy and diagnostics. Tetrahedron. 2012;68(42):8767-8772. doi:10.1016/j. tet.2012.08.007

18. Halma M, Bail A, Wypych F, Nakagaki S. Catalytic activity of anionic iron(III) porphyrins immobilized on grafted disordered silica obtained from acidic leached chrysotile. J Mol Catal A Chem. 2006;243(1):4451. doi:10.1016/j.molcata.2005.08.019

19. Ghosh A. Substituent Effects on Valence Ionization Potentials of Free Base Porphyrins: Local Density Functional Calculations and Their Relevance to Electrochemical and Photoelectron Spectroscopic Studies. J Am Chem Soc. 1995;117(16):4691-4699. doi:10.1021/ja00121a025

20. Liu W, Groves JT. Manganese porphyrins catalyze selective $\mathrm{C}-\mathrm{H}$ bond halogenations. J Am Chem Soc. 2010;132(37):12847-12849. doi:10.1021/ja105548x

21. Wolfe JP, Wagaw S, Buchwald SL. An improved catalyst system for aromatic carbon-nitrogen bond formation: The possible involvement of bis(phosphine) palladium complexes as key intermediates. J Am Chem Soc. 1996;118(30):7215-7216. doi:10.1021/ja9608306

22. Scandola F, Chiorboli C, Prodi A, lengo E, Alessio E. Photophysical properties of metal-mediated assemblies of porphyrins. Coord Chem Rev. 2006;250(11-12):1471-1496. doi:10.1016/j.ccr.2006.01.019

23. Mahmoudi M, Serpooshan V. Silver-coated engineered magnetic nanoparticles are promising for the success in the fight against antibacterial resistance threat. ACS Nano. 2012;6(3):2656-2664. doi:10.1021/nn300042m

24. Georganopoulou DG, Chang L, Nam J, et al. Nanoparticle-Based Detection in Cerebral Spinal Fluid of a Soluble Pathogenic Biomarker for Alzheimer 's Disease Linked references are available on JSTOR for this article : Nanoparticle-based detection in cerebral spinal fluid of a soluble pathogenic bio. Published online 2016.

25. Benelli G. Green synthesized nanoparticles in the fight against mosquito-borne diseases and cancer-abrief review. Enzyme Microb Technol. 2016;95:58-68. doi:10.1016/j.enzmictec.2016.08.022

26. Liu W, Zhu Z, Deng K, et al. Gold nanorod@Chiral mesoporous silica core-shell nanoparticles with unique optical properties. J Am Chem Soc. 2013;135(26):9659-9664. doi:10.1021/ja312327m 
27. Li CZ, Male KB, Hrapovic S, Luong JHT. Fluorescence properties of gold nanorods and their application for DNA biosensing. Chem Commun. 2005;(31):3924-3926. doi:10.1039/b504186d

28. Niidome T, Yamagata M, Okamoto $Y$, et al. PEG-modified gold nanorods with a stealth character for in vivo applications. J Control Release. 2006;114(3):343-347. doi:10.1016/j.jconrel.2006.06.017

29. Khalavka Y, Becker J, Sönnichsen C. Synthesis of rod-shaped gold nanorattles with improved plasmon sensitivity and catalytic activity. J Am Chem Soc. 2009;131(5):1871-1875. doi:10.1021/ja806766w

30. Eustis S, El-Sayed MA. Determination of the aspect ratio statistical distribution of gold nanorods in solution from a theoretical fit of the observed inhomogeneously broadened longitudinal plasmon resonance absorption spectrum. J Appl Phys. 2006;100(4). doi:10.1063/1.2244520

31. Zhu J, Li JJ, Zhao JW, Bai SW. Light absorption efficiencies of gold nanoellipsoid at different resonance frequency. J Mater Sci. 2008;43(15):5199-5205. doi:10.1007/s10853-008-2751-6

32. Stone J, Jackson S, Wright D. Biological applications of gold nanorods. Wiley Interdiscip Rev Nanomedicine Nanobiotechnology. 2011;3(1):100-109. doi:10.1002/wnan.120

33. Murphy CJ, Gole AM, Hunyadi SE, et al. Chemical sensing and imaging with metallic nanorods. Chem Commun. 2002;8(5):544557. doi:10.1039/b711069c

34. Maestrin APJ, Ribeiro AO, Tedesco AC, et al. A novel chlorin derivative of meso-tris(pentafluorophenyl)-4- pyridylporphyrin: Synthesis, photophysics and photochemical properties. J Braz Chem Soc. 2004;15(6):923-930. doi:10.1590/S0103-50532004000600021

35. Lazzeri D, Durantini EN. Synthesis of meso-substituted cationic porphyrins as potential photodynamic agents. Arkivoc. 2003;2003(10):227. doi:10.3998/ark.5550190.0004.a23

36. Luguya R, Jaquinod L, Fronczek FR, Vicente MGH, Smith KM. Synthesis and reactions of meso-(p-nitrophenyl)porphyrins. Tetrahedron. 2004;60(12):2757-2763. doi:10.1016/j.tet.2004.01.080

37. Saad S, Taher M, Susanti D, Qaralleh H, Awang AFIB. In vitro antimicrobial activity of mangrove plant Sonneratia alba. Asian Pac J Trop Biomed. 2012;2(6):427-429. doi:10.1016/S22211691(12)60069-0

38. Eloff JN. Quantifying the bioactivity of plant extracts during screening and bioassay-guided fractionation. Phytomedicine. $2004 ; 11: 370-371$.

39. Maliehe TS, Shandu JS, Basson AK. The antibacterial and antidiarreal activities of the crude methanolic Syzygium cordatum [S.Ncik, 48 (UZ)] fruit pulp and seed extracts. J Med Plants Res. 2015;9(33):884-891. doi:10.5897/jmpr2015.5789

40. Amos-Tautua BM, Songca SP, Oluwafemi OS. Application of porphyrins in antibacterial photodynamic therapy. Molecules. 2019;24(13). doi:10.3390/molecules24132456
41. Allouche A. Software News and Updates Gabedit - A Graphical User Interface for Computational Chemistry Softwares. J Comput Chem. 2012;32:174-182. doi:10.1002/jcc

42. Acar C, Yalçın G, Ertan-Bolelli T, et al. Synthesis and molecular docking studies of some novel antimicrobial benzamides. Bioorg Chem. 2020;94:103368. doi:10.1016/j.bioorg.2019.103368

43. Daina A, Michielin O, Zoete V. SwissADME: A free web tool to evaluate pharmacokinetics, drug-likeness and medicinal chemistry friendliness of small molecules. Sci Rep. 2017;7(March):1-13. doi:10.1038/srep42717

44. Dong J, Wang NN, Yao ZJ, et al. Admetlab: A platform for systematic ADMET evaluation based on a comprehensively collected ADMET database. J Cheminform. 2018;10(1):1-11. doi:10.1186/s13321018-0283-x

45. Wang $Y, X i n g ~ J, X u Y$, et al. In silico ADME/T modelling for rational drug design. $Q$ Rev Biophys. 2015;48(4):488-515. doi:10.1017/ S0033583515000190

46. Basant N, Gupta S, Singh KP. Predicting human intestinal absorption of diverse chemicals using ensemble learning based QSAR modeling approaches. Comput Biol Chem. 2016;61:178-196. doi:10.1016/j.compbiolchem.2016.01.005

47. Ilieva Y, Kokanova-Nedialkova Z, Nedialkov P, Momekov G. In silico ADME and drug-likeness evaluation of a series of cytotoxic polyprenylated acylphloroglucinols, isolated from Hypericum annulatum Morris subsp. annulatum. Bulg Chem Commun. 2018;50(August):193-199.

48. Maliehe TS, Tsilo PH, Shandu JS, Tsilo PH. Computational Evaluation of ADMET Properties and Bioactive Score of Compounds from Encephalartos ferox. 2020;12(6):1-6.

49. Tyzack JD, Mussa HY, Williamson MJ, Kirchmair J, Glen RC Cytochrome $\mathrm{P} 450$ site of metabolism prediction from 2D topological fingerprints using GPU accelerated probabilistic classifiers. J Cheminform. 2014;6(1):1-14. doi:10.1186/1758-2946-6-29

50. Dobo KL, Obach RS, Luffer-Atlas D, Bercu JP. A strategy for the risk assessment of human genotoxic metabolites. Chem Res Toxicol. 2009;22(2):348-356. doi:10.1021/t×8004339

51. Yang ZY, He JH, Lu AP, Hou TJ, Cao DS. Application of negative design to design a more desirable virtual screening library. J Med Chem. 2020;63(9):4411-4429. doi:10.1021/acs.jmedchem.9b01476

52. Mathieu B, Bertrand L, Peyrusse V, Schaffner F, Bertrand M Culicidae and water mites: Parasitism under mediterranean climatic conditions. Acarologia. 2007;47(1-2):55-61.

53. Kuete $V$. Potential of Cameroonian plants and derived products against microbial infections: A review. Planta Med. 2010;76(14):1479-1491. doi:10.1055/s-0030-1250027 


\section{GRAPHICAL ABSTRACT}

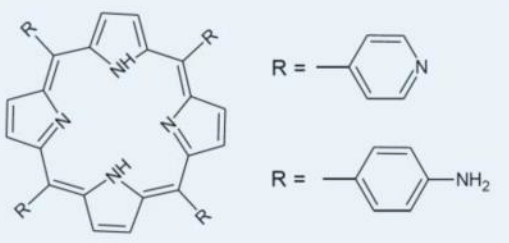

$=$
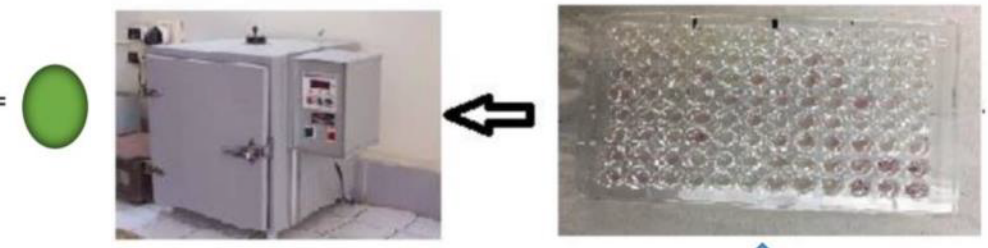

MTT Assay
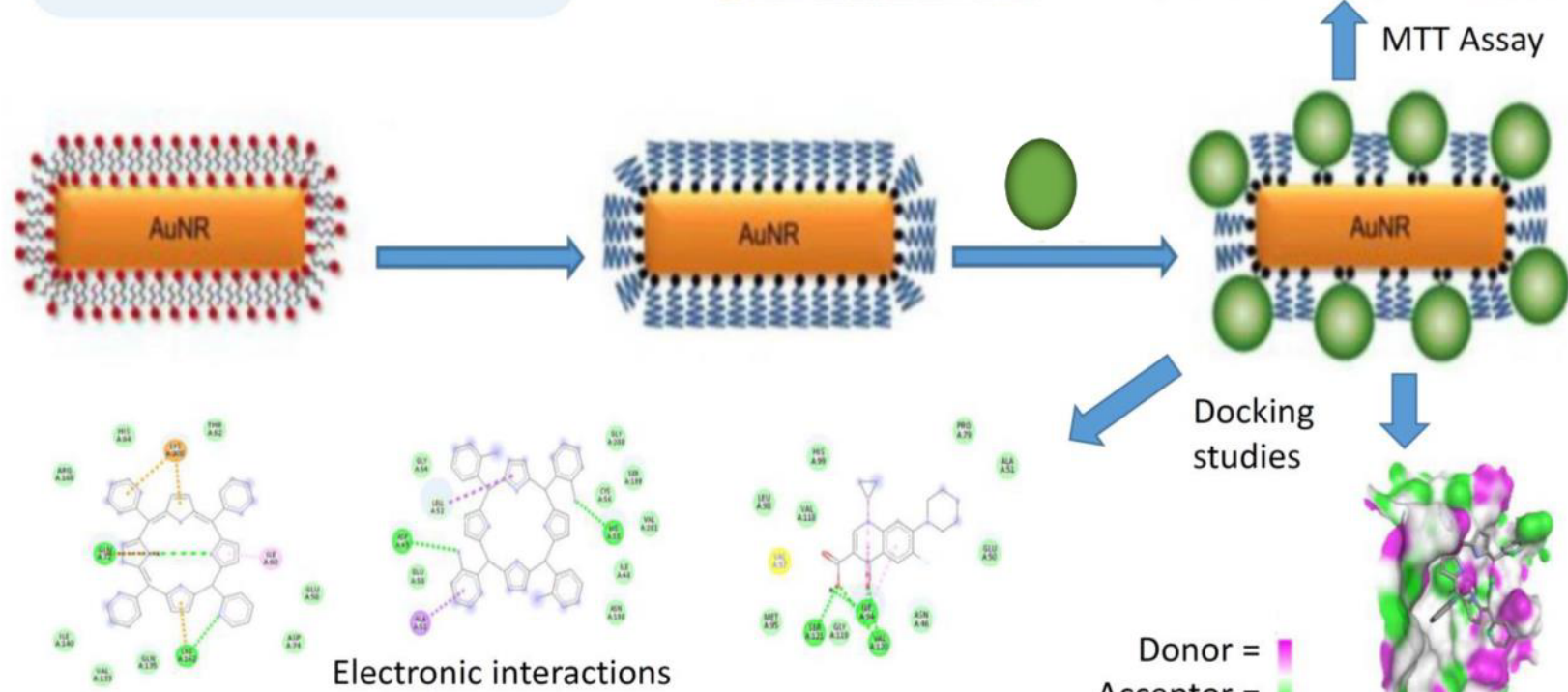

Electronic interactions
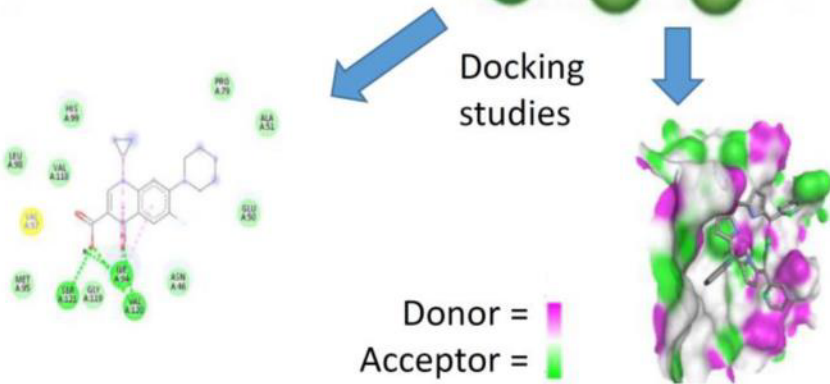

\section{ABOUT AUTHORS}

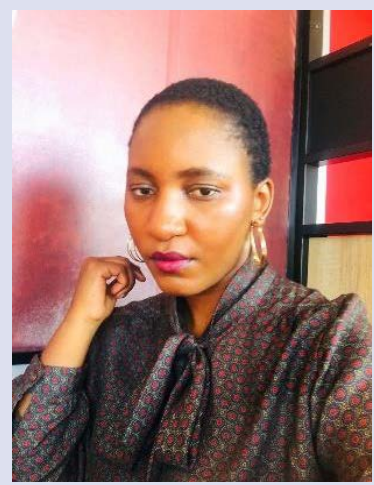

Nthabeleng Hlapisi holds a BSc degree in Chemistry and Geography from the National University of Lesotho, a BSc Honours degree from the University of the Free State and an MSc degree in Organic chemistry from the University of Zululand. Her research project was based on the encapsulation of gold nanorods using porphyrins for the potential treatment of cancer and bacterial infections. Her research interests include the use of nanoparticles, multimodal theragnostic methods, photochemistry and bioinformatics to further enhance drug synthesis and delivery studies. She has her work published in different accredited journals.

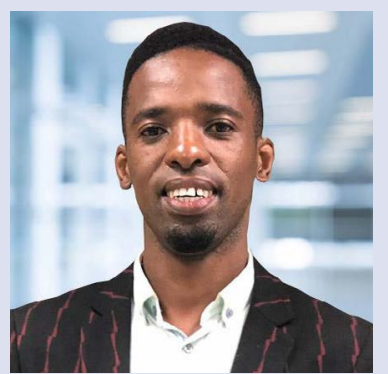

Dr TS. Maliehe holds a BSc degree in Biotechnology and BSc-Honours, MSc and PhD in Microbiology from the University of Zululand. He is a postdoctoral fellow in the same institution. His research expertise falls within Environmental Microbiology with an emphasis on wastewater treatment using microbial bioflocculants. He is an expert in bioactive compounds of health importance from microbial origin (endophytes) and plants. He is also well informed in Bioinformatics. He has collaborated with a large number of researchers and academics and published his work in highly rated accredited journals. 


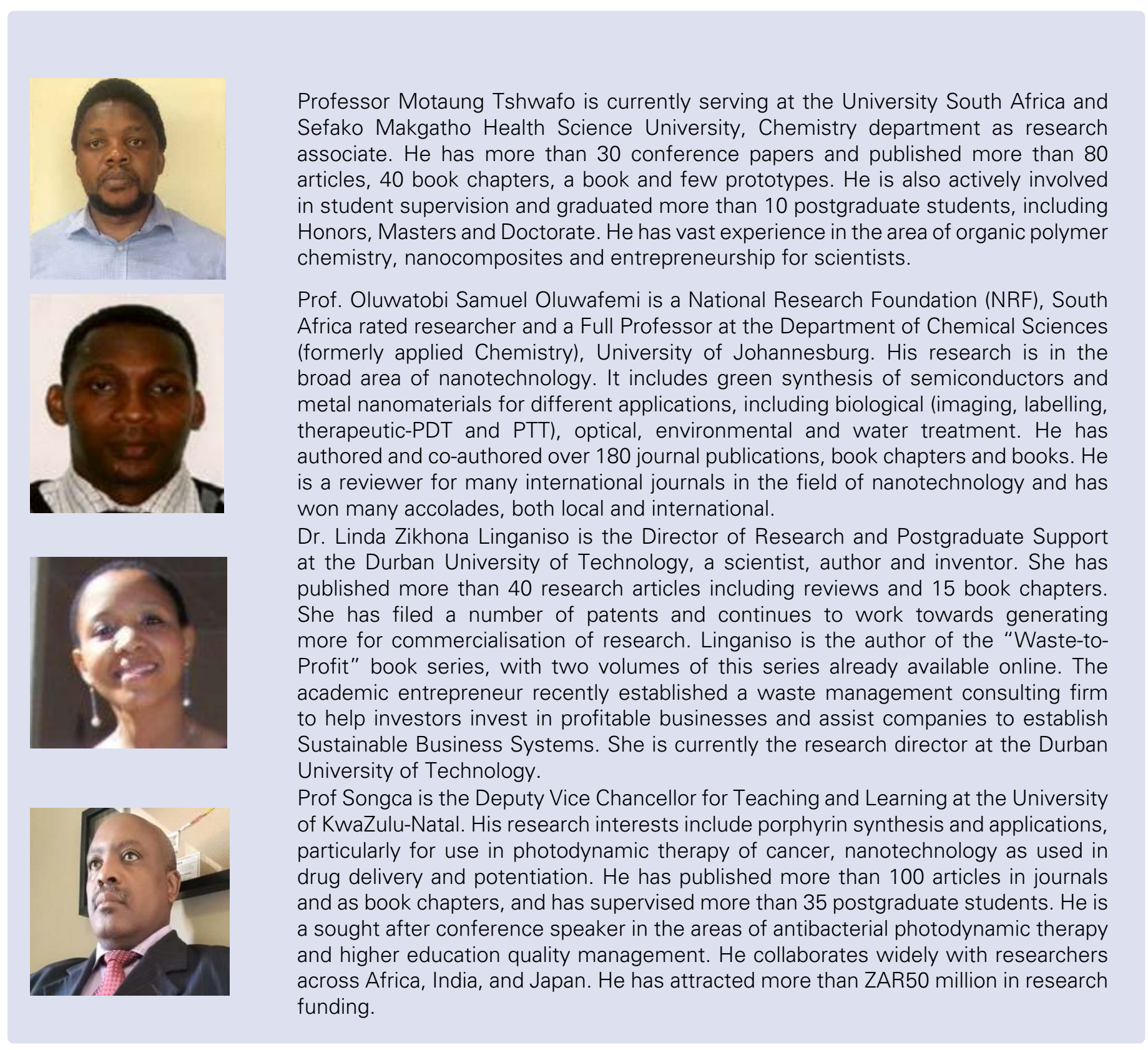

Cite this article: Hlapisi N, Maliehe TS, Oluwafemi OS, Songca SP, Linganiso L, Motaung TE. Antibacterial Activities of Cationic Porphyrins and Gold Nanorod Encapsulated Porphyrins on Bacterial Cell Lines. Pharmacogn J. 2021;13(5): $1086-1096$. 